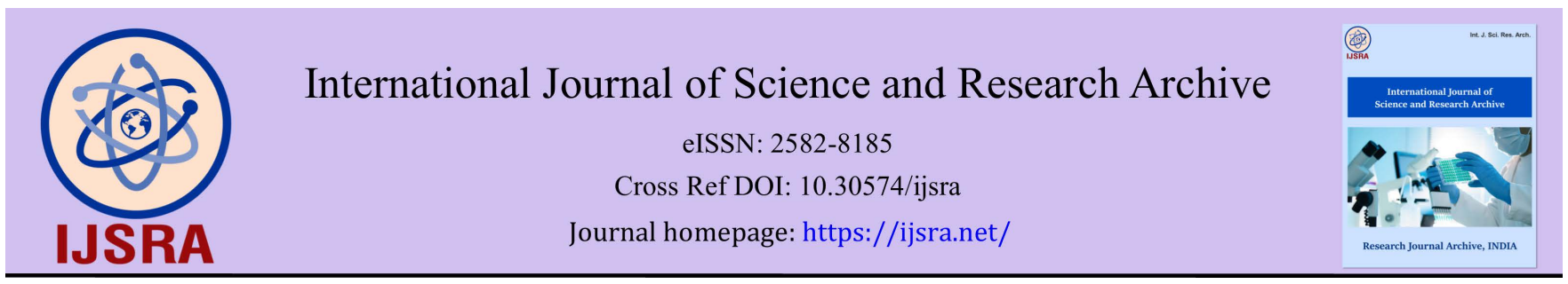

(RESEARCH ARTiClE)

\title{
Evaluating health related quality of life among hypertensive patients: An educational intervention study
}

\author{
Biobarakuma A Joseph 1, Joshua F Eniojukan ${ }^{1}$, Ismail A Suleiman ${ }^{1}$ and Timothy G Anthony 2,* \\ ${ }^{1}$ Department of Clinical Pharmacy \& Pharmacy Practice, Faculty of Pharmacy, Niger Delta University, Bayelsa State, \\ Nigeria. \\ 2 Department of Pharmacy Technician Studies, School of Allied Medical Science, College of Health Technology, Otuogidi, \\ Bayelsa State, Nigeria.
}

International Journal of Science and Research Archive, 2022, 05(02), 001-008

Publication history: Received on 15 January 2022; revised on 24 February 2022; accepted on 26 February 2022

Article DOI: https://doi.org/10.30574/ijsra.2022.5.2.0052

\begin{abstract}
The health care sector has shown increased interest in humanistic outcomes of therapy. Health related quality of life (HRQOL) evaluation among patients receiving treatment for chronic diseases is now widely applied. Hence, the effect of education on the HRQOL of hypertensive patients was evaluated in two tertiary health facilities; FMC, Yenagoa and NDUTH, Okolobiri in Bayelsa State, Nigeria. Trained Pharmacist interviewed willing hypertensive patients between 2180 years of age at the cardiology clinics of the health facilities using the MINICHAL questionnaire which is specific for hypertension. A convenient sampling technique was adopted. Demographic characteristics were also obtained. The responses (425) were analyzed and observed. To evaluate the effect of drugs and educational intervention, an interactive health talks on hypertension was held at their cardiology clinic weekly for six weeks. Two months later the questionnaire was re-administered. The responses post intervention (297) was analyzed. The results were then compared. The MINICHAL rates HRQOL as best $=0$ to worst=51. HRQOL score of 12.96 to 8.00 in FMC Yenagoa and 8.70 to 8.55 in NDUTH Okolobiri, pre and post intervention respectively was observed. Though not significant $(\mathrm{P}=0.3998)$, the study revealed that educational intervention brought about a positive trend in demographic characteristics. Age, marriage and education were indicated as strong indicators of HRQOL. Educational intervention on hypertension improves patient's HRQOL. Patients' education and counseling should be a continuous tool in patient management.
\end{abstract}

Keywords: Hypertension; Health Related Quality of Life; Hypertensive Patients; Educational Intervention

\section{Introduction}

Quality of life of a person can be assessed subjectively and objectively by the economic, clinical and humanistic outcomes and of physical, material, social, and emotional indicators after a course of a particular treatment [1]. However, health related quality of life is that aspect of quality of life that relates to the functional effect of the presence of a disease and of it' therapy on a person. How well a person function (carry out some pre-defined activities or functions in their life) and his or her perceived wellbeing (individual's subjective feelings) in physical, mental, and social domains of healthcare direct functions of the disease state involved [2,3]. Health related quality of life (HRQOL) or its values and utilities can be assessed by the QALY which is a measure of health on a scale from zero (0) as being dead and one (1) as the best HRQOL [4,5]. Hypertension is a multifactorial clinical condition characterized by high and sustained levels of blood pressure with the propensity of development of cardiovascular diseases [6]. It is observed to progress with mild or no symptoms for years until it is diagnosed or consequences of end-organ damage becomes evident [7]. On diagnosis, the management requirements include those of chemotherapy and lifestyle changes, but adherence to the above have been found to be low, and thus a consequent reported poor quality of health [8-12]. Studies have also shown that, even with

${ }^{*}$ Corresponding author: Biobarakuma A Joseph

Department of Clinical Pharmacy and Pharmacy Practice, Faculty of Pharmacy, Niger Delta University, Bayelsa State, Nigeria.

Copyright (c) 2022 Author(s) retain the copyright of this article. This article is published under the terms of the Creative Commons Attribution Liscense 4.0. 
adherence to drug management, quality of life seem not to improve, partly because of the pattern of the disease progression [13]. Awareness in the form of educational intervention has reported positive attitude to treatments [14, 15] and improved quality of life in literature [16]. Instruments used for assessing QOL in hypertensive individuals, such as the MINICHAL Scale (Mini Cuestionario de Calidad de Vida en Hipertension Arterial), among others, has been shown be useful.

Bayelsa state of Nigeria is not free of the scourge of hypertension. The literature search did report the research efforts of some scholars in the Niger Delta region, such as the work on health related quality of life of hypertensive and diabetic patients by Ganiyu et al 2015 [18] and that of arthritis and diabetes patients by Suleiman et al, 2016 [19], among others. The main goal of the study is to describe the management of hypertension in two Nigerian tertiary health facilities in Bayelsa state of Nigeria with a view to observing similarities and differences observed in all facets and steps of management.

\section{Material and methods}

\subsection{Participant selection}

A cross-sectional prospective study was carried out using convenient sampling technique. Four hundred and twenty five (425) hypertensive patients were interviewed for the pre-intervention which comprised of 169 in NDUTH Okolobiri and 256 in FMC Yenagoa. The post-intervention was executed by interviewing 297 participants. This was made up of 153 patients in FMC Yenagoa and 144 patients in NDUTH Okolobiri. Participants were aged 21 to 80 years, diagnosed of hypertension and had been attending the medical outpatient and cardiology clinics of the two health facilities.

\subsection{Administration and intervention}

The MINCHAL Scale questionnaire for hypertension was administered to consented participants by trained pharmacists who interviewed the patients on their clinic days and entered their respective responses into the study instrument directly. The MINICHAL (Mini Cuestionario de Calidad de Vida en Hipertension Arterial) scale is a specific tool for assessing QOL in hypertensive individuals. It consists of two domains-mental (nine items) and somatic (seven items). The mental domain includes questions 1-9 and scores range from 0-27points whereas the somatic domain includes questions 10-16 and scores range from 0-21points. The last question is related to the overall impact of hypertension on the QOL. The score scale is likert scale with four possible answers $(0=$ No, not at all; $1=$ Yes, somewhat; $2=$ Yes a lot; $3=$ Yes, very much,). Total points range from 0 (best level of Health) to 51 (worst level of Health). An analysis of the preintervention responses was carried out followed by six week duration of educational intervention. Two hundred and ninety-seven (297) participants in all, FMC Yenagoa (153) and NDUTH Okolobiri (144) consented to partake in the study. The intervention was a forty five (45) minutes long health talk given to participants on their weekly clinic days in the cardiology units. Two months after the intervention, the study instrument was repeated using the same pattern. The same analysis was repeated and the two HRQOL compared for trend.

\section{Results and discussion}

The participants of the study were more of females (52.7\%) within the age brackets of 40 to 60 (53\%), married (75.39\%) and living with adults $(81.25 \%)$ having minimum secondary education (75.7\%) and in government employment (56.25\%) (Table 1). The study recorded an improvement in health-related quality of life after the educational intervention. The result follows the trend of HRQOL score of 12.96 to 8.00 in FMC Yenagoa and that of 8.70 to 8.55 in NDUTH Okolobiri, Bayelsa state, Nigeria. This represents 4.96 units and 0.15 unit improvements in HRQOL in FMC and NDUTH respectively. In the MINICHAL scale, 0 stands for best quality of life and 1 stands for worst quality of life. This is as shown in Table 2. Paired t-test revealed two-tailed P value of $0.3998, t=1.377$ with 1 degrees of freedom, meaning that the degree of change experienced was not considered significant. The improved effect of the intervention was revealed by almost all demographic characteristics, except for males below the age of 40 and those above 60 years, single, living alone or with children, with low education and unemployment (Table 3). Chi-square test on Quality of life and patient baseline characteristics revealed age, marriage and education as strong indicators of HRQOL (Table 4). 
Table 1 Demographic characteristics of respondents $(\mathrm{N}=425)$

\begin{tabular}{|c|c|c|c|}
\hline \multicolumn{4}{|c|}{ Demographic characteristics of hypertensive patients in Bayelsa State } \\
\hline Item & Response label & Count & Percentage \\
\hline \multirow{2}{*}{ Gender } & Male & 201 & $47.27 \%$ \\
\hline & Female & 224 & $52.73 \%$ \\
\hline \multirow{4}{*}{ Age group } & $<40$ & 38 & $8.98 \%$ \\
\hline & $40-50$ & 111 & $26.17 \%$ \\
\hline & $51-60$ & 115 & $26.95 \%$ \\
\hline & $>60$ & 161 & $37.89 \%$ \\
\hline \multirow{4}{*}{ Marital status } & Married & 320 & $75.39 \%$ \\
\hline & Single & 32 & $7.42 \%$ \\
\hline & Div/widow/separated & 71 & $16.80 \%$ \\
\hline & Unclassified & 2 & $0.39 \%$ \\
\hline \multirow{4}{*}{ Living } & Alone & 60 & $14.06 \%$ \\
\hline & With adults & 345 & $81.25 \%$ \\
\hline & With only children $<16 y r s$ & 5 & $1.17 \%$ \\
\hline & Complex & 15 & $3.52 \%$ \\
\hline \multirow{4}{*}{ Education } & No school & 32 & $7.42 \%$ \\
\hline & Primary & 68 & $16.02 \%$ \\
\hline & Secondary & 159 & $37.50 \%$ \\
\hline & Tertiary & 163 & $38.28 \%$ \\
\hline \multirow{5}{*}{ Occupation } & Gov. Staff/ retiree & 239 & $56.25 \%$ \\
\hline & Private sector staff/ retiree & 27 & $6.25 \%$ \\
\hline & Self employed & 101 & $23.83 \%$ \\
\hline & Unemployed & 43 & $10.16 \%$ \\
\hline & Retired from self-employment & 10 & $2.34 \%$ \\
\hline
\end{tabular}


Table 2 Quality of Life in FMC Yenagoa and NDUTH Okolobiri Pre and Post Intervention

\begin{tabular}{|c|c|c|c|c|c|c|c|c|c|c|c|c|c|c|c|c|c|}
\hline \multicolumn{18}{|c|}{ Quality of Life of hypertensive patients in FMC Yenagoa and NDUTH Okolobiri Pre and Post Intervention, Bayelsa State Nigeria } \\
\hline & \multirow[b]{2}{*}{ Question items } & \multicolumn{4}{|c|}{ FMC Pre (256) } & \multicolumn{4}{|c|}{ FMC Post (152) } & \multicolumn{4}{|c|}{ NDUTH Pre(169) } & \multicolumn{4}{|c|}{ NDUTH Post(144) } \\
\hline & & 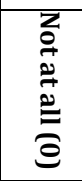 & $\stackrel{\S}{\Xi}$ & 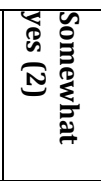 & 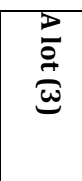 & $\begin{array}{l}z \\
\vdots \\
\ddot{\Xi} \\
\ddot{\Xi} \\
0\end{array}$ & $\stackrel{8}{\Xi}$ & 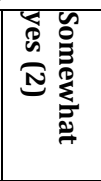 & 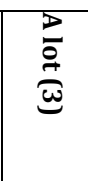 & $\begin{array}{l}z \\
\stackrel{2}{0} \\
\stackrel{2}{0} \\
\stackrel{\Xi}{0}\end{array}$ & $\stackrel{\circledR}{\Xi}$ & 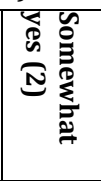 & 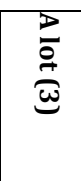 & 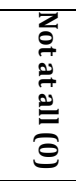 & 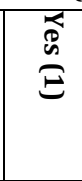 & 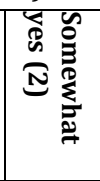 & 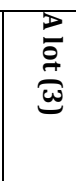 \\
\hline HQ1 & Have you been sleeping poorly & 130 & 69 & 50 & 7 & 119 & 15 & 19 & 0 & 78 & 59 & 31 & 1 & 110 & 13 & 18 & 3 \\
\hline HQ2 & $\begin{array}{l}\text { Have you had difficulty maintaining your usual social } \\
\text { relationships? }\end{array}$ & 161 & 60 & 30 & 5 & 116 & 7 & 18 & 0 & 147 & 11 & 10 & 1 & 73 & 60 & 11 & 0 \\
\hline HQ3 & Have you had difficulty interacting with other people? & 177 & 45 & 31 & 3 & 146 & 3 & 2 & 2 & 148 & 13 & 6 & 1 & 117 & 16 & 10 & 1 \\
\hline HQ4 & Have you felt that you are not playing a useful role in life? & 166 & 45 & 38 & 7 & 124 & 23 & 4 & 2 & 148 & 15 & 6 & 0 & 67 & 62 & 15 & 0 \\
\hline HQ5 & $\begin{array}{l}\text { Have you felt unable to make decisions and start new } \\
\text { things/projects? }\end{array}$ & 172 & 49 & 29 & 20 & 145 & 6 & 2 & 0 & 138 & 24 & 6 & 0 & 101 & 20 & 23 & 0 \\
\hline HQ6 & Have you felt continuously distressed and tense? & 130 & 53 & 62 & 11 & 36 & 38 & 79 & 0 & 122 & 25 & 21 & 1 & 46 & 69 & 29 & 0 \\
\hline HQ7 & Have you felt that life is a constant struggle? & 120 & 66 & 50 & 20 & 116 & 14 & 22 & 1 & 106 & 42 & 17 & 4 & 97 & 40 & 6 & 1 \\
\hline HQ8 & Have you felt incapable of enjoying your daily activities? & 139 & 70 & 37 & 10 & 117 & 4 & 32 & 0 & 119 & 30 & 16 & 3 & 85 & 52 & 5 & 2 \\
\hline HQ9 & Have you felt worn- out and powerless? & 97 & 101 & 44 & 14 & 95 & 10 & 47 & 1 & 104 & 41 & 22 & 2 & 78 & 64 & 2 & 0 \\
\hline HQ10 & Have you felt sick? & 51 & 151 & 41 & 13 & 61 & 51 & 33 & 0 & 51 & 84 & 29 & 3 & 74 & 44 & 26 & 0 \\
\hline HQ11 & $\begin{array}{l}\text { Have you had difficulty breathing or felt breathless for no } \\
\text { apparent reason? }\end{array}$ & 137 & 55 & 58 & 6 & 131 & 11 & 10 & 1 & 114 & 33 & 21 & 1 & 88 & 53 & 2 & 1 \\
\hline HQ12 & Have your ankles been swollen? & 124 & 81 & 44 & 7 & 133 & 18 & 2 & 0 & 79 & 77 & 12 & 1 & 88 & 50 & 6 & 0 \\
\hline HQ13 & $\begin{array}{l}\text { Have you noticed that you are urinating more } \\
\text { frequently? }\end{array}$ & 132 & 77 & 40 & 7 & 97 & 13 & 37 & 0 & 76 & 67 & 25 & 1 & 82 & 57 & 4 & 1 \\
\hline HQ14 & Has your mouth been dry? & 141 & 62 & 49 & 4 & 127 & 8 & 15 & 1 & 88 & 45 & 35 & 1 & 95 & 37 & 9 & 3 \\
\hline HQ15 & $\begin{array}{l}\text { Have you felt pain in the chest without doing any } \\
\text { physical exertion? }\end{array}$ & 125 & 79 & 47 & 5 & 90 & 18 & 45 & 0 & 94 & 50 & 25 & 0 & 103 & 32 & 9 & 0 \\
\hline HQ16 & $\begin{array}{l}\text { Have you noticed numbness or a tingling sensation in } \\
\text { any part of the body? }\end{array}$ & 111 & $87 s$ & 48 & 10 & 111 & 18 & 24 & 0 & 96 & 48 & 23 & 2 & 98 & 44 & 2 & 0 \\
\hline \multirow[t]{3}{*}{ HQ17 } & $\begin{array}{l}\text { Would you say that your hypertension and it's treatment } \\
\text { has affected your quality of life? }\end{array}$ & 61 & 105 & 49 & 41 & 23 & 14 & 116 & 0 & 77 & 51 & 30 & 11 & 103 & 23 & 16 & 2 \\
\hline & Subtotal HRQOL & 0.00 & 4.90 & 5.83 & 2.23 & 0.00 & 1.77 & 6.63 & 0.16 & 0.00 & 4.23 & 3.96 & 0.59 & 0.00 & 5.11 & 2.68 & 0.29 \\
\hline & Total HRQOL & \multicolumn{4}{|l|}{12.96} & \multicolumn{4}{|l|}{8.55} & \multicolumn{4}{|l|}{8.78} & \multicolumn{4}{|l|}{8.08} \\
\hline
\end{tabular}


Table 3 Quality of life and demographic characteristics (pre and post intervention) for FMC and NDUTH

\begin{tabular}{|c|c|c|c|c|c|}
\hline \multicolumn{6}{|c|}{$\begin{array}{l}\text { Quality of life and demographic characteristics of hypertensive patients (pre and post intervention) for } \\
\text { FMC and NDUTH, Bayelsa state, Nigeria }\end{array}$} \\
\hline \multirow[t]{2}{*}{ Item } & \multirow[t]{2}{*}{ Response } & \multicolumn{4}{|c|}{ Institution } \\
\hline & & $\begin{array}{l}\text { FMC Pre } \\
\text { (256) }\end{array}$ & $\begin{array}{l}\text { FMC Post } \\
\text { (153) }\end{array}$ & $\begin{array}{l}\text { NDUTH Pre } \\
\text { (169) }\end{array}$ & $\begin{array}{l}\text { NDUTH Post } \\
\text { (144) }\end{array}$ \\
\hline \multirow[t]{2}{*}{ Gender } & Male & 6.26 & 3.42 & 4.04 & 5.24 \\
\hline & Female & 6.54 & 5.14 & 4.75 & 2.80 \\
\hline \multirow[t]{4}{*}{ Age group } & $<40$ & 0.91 & 2.54 & 6.57 & 2.09 \\
\hline & $40-50$ & 3.61 & 1.99 & 1.16 & 1.06 \\
\hline & $51-60$ & 3.49 & 2.58 & 1.02 & 2.99 \\
\hline & $>60$ & 4.8 & 1.45 & 0 & 1.90 \\
\hline \multirow[t]{4}{*}{ Marit.al status } & Married & 9.54 & 5.43 & 6.57 & 4.17 \\
\hline & Single & 0.97 & 1.88 & 1.16 & 1.31 \\
\hline & Divorced/widow/separated & 2.29 & 1.26 & 1.05 & 2.56 \\
\hline & Unclassified & 0.00 & 0.00 & 0.00 & 0.00 \\
\hline \multirow[t]{4}{*}{ Living } & Alone & 1.8 & 0.71 & 0.95 & 2.10 \\
\hline & With adults & 10.6 & 6.33 & 6.98 & 4.59 \\
\hline & With children $<16 y r s$ & 0.13 & 0.85 & 0.79 & 1.31 \\
\hline & Complex & 0.28 & 0.67 & 0.07 & 0.03 \\
\hline \multirow[t]{4}{*}{ Education } & No school & 1.26 & 0.58 & 0.66 & 0.25 \\
\hline & Primary & 2.07 & 0.19 & 0.74 & 1.45 \\
\hline & Secondary & 5.0 & 2.58 & 2.62 & 3.53 \\
\hline & Tertiary & 4.38 & 5.21 & 5.15 & 2.74 \\
\hline \multirow[t]{6}{*}{ Occupation } & Gov. Staff/ retired & 7.11 & 5.81 & 6.33 & 5.54 \\
\hline & Private sector staff & 0.98 & 0.40 & 0.65 & 0.53 \\
\hline & Self employed & 3.17 & 2.10 & 1 & 1.13 \\
\hline & Unemployed & 1.07 & 0.25 & 0.25 & 0.56 \\
\hline & Retired from self-employ & 0.41 & 0.00 & 0.28 & 0.27 \\
\hline & TOTAL QOL & 12.96 & 8.55 & 8.78 & 8.08 \\
\hline
\end{tabular}


International Journal of Science and Research Archive, 2022, 05(02), 001-008

Table 4 Chi-square test on quality of life and baseline characteristics (FMC Yenagoa and NDUTH Okolobiri pre and post intervention

\begin{tabular}{|c|c|c|c|c|c|c|c|c|c|c|c|c|c|c|c|c|c|c|c|c|c|c|c|c|}
\hline \multirow{4}{*}{$\mathrm{N} \quad \mathrm{O}$} & \multicolumn{24}{|c|}{ Chi-square test on quality of life and baseline characteristics of hypertensive patients (FMC Yenagoa and NDUTH Okolobiri pre and post intervention, Bayelsa state, Nigeria } \\
\hline & \multicolumn{4}{|c|}{ Gender } & \multicolumn{4}{|c|}{ Age } & \multicolumn{4}{|c|}{ Marriage } & \multicolumn{4}{|c|}{ Living status } & \multicolumn{4}{|c|}{ Education } & \multicolumn{4}{|c|}{ Occupation } \\
\hline & \multicolumn{2}{|c|}{ FMC } & \multicolumn{2}{|c|}{ NDUTH } & \multicolumn{2}{|c|}{ FMC } & \multicolumn{2}{|c|}{ NDUTH } & \multicolumn{2}{|c|}{ FMC } & \multicolumn{2}{|c|}{ NDUTH } & \multicolumn{2}{|c|}{ FMC } & \multicolumn{2}{|c|}{ NDUTH } & \multicolumn{2}{|c|}{ FMC } & \multicolumn{2}{|c|}{ NDUTH } & \multicolumn{2}{|c|}{ FMC } & \multicolumn{2}{|c|}{ NDUTH } \\
\hline & $\overline{0}$ & 矛 & हैं & 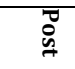 & $\overline{0}$ & 离 & चี & $\overline{0}$ & $\overline{0}$ & 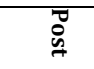 & $\overline{7}$ & $\bar{\square}$ & $\overline{7}$ & $\bar{\square}$ & $\overline{7}$ & $\bar{D}$ & $\overline{0}$ & 矛 & $\overline{0}$ & 总 & वैं & $\overline{\mathscr{0}}$ & $\bar{\nabla}$ & $\overline{0}$ \\
\hline 1 & 0.700 & 0.700 & 0.500 & 0.100 & 0.900 & $0.020^{*}$ & 0.500 & $0.00^{*}$ & 0.000 & 0.000 & 0.500 & 0.300 & 0.900 & 0.100 & 0.000 & 0.400 & 0.200 & $0.008^{*}$ & 0.600 & 0.100 & 0.400 & 0.200 & 0.900 & 0.800 \\
\hline 2 & 0.600 & $0.042^{*}$ & 0.200 & 0.000 & 0.600 & 0.100 & 0.100 & $0.04^{*}$ & 0.700 & 0.500 & 0.100 & 0.100 & 0.900 & 0.400 & 1.000 & 0.200 & 0.100 & 0.800 & $0.03^{*}$ & 0.200 & 0.200 & 0.600 & 1.000 & $0.00^{*}$ \\
\hline 3 & 0.700 & 0.200 & 0.700 & 0.600 & 0.400 & 0.200 & 0.100 & 0.200 & 1.000 & 0.200 & 0.100 & 0.800 & 0.700 & $0.005^{*}$ & 1.000 & 0.900 & 0.000 & $0.006^{*}$ & 0.500 & 0.200 & 0.400 & 0.600 & 0.900 & 0.300 \\
\hline 4 & 0.200 & 0.400 & 0.800 & 0.000 & 0.400 & 0.200 & 0.600 & $0.01^{*}$ & 0.700 & 0.200 & 0.600 & $0.00^{*}$ & 0.800 & $0.006^{*}$ & 0.700 & 0.000 & 0.000 & $0.002^{*}$ & 0.300 & $0.00^{*}$ & 1.000 & 0.600 & 0.900 & 0.200 \\
\hline 5 & 0.300 & 0.500 & 0.700 & 0.300 & 0.100 & 0.100 & 0.000 & 0.300 & 0.800 & $0.039^{*}$ & 0.000 & $0.00^{*}$ & 1.000 & 0.400 & 0.100 & 0.500 & 0.100 & $0.033^{*}$ & 0.700 & $0.00^{*}$ & 0.900 & 0.800 & 0.400 & 0.200 \\
\hline 6 & 0.400 & 1.000 & 0.100 & 0.800 & 0.400 & 0.400 & 0.900 & 0.100 & 0.900 & $0.001^{*}$ & 0.900 & 0.200 & 0.900 & 0.700 & 1.000 & 0.100 & 0.100 & 0.500 & 1.000 & 0.000 & 0.400 & 0.300 & 0.900 & 0.300 \\
\hline 7 & 0.200 & 0.900 & 0.100 & 0.400 & 0.000 & 0.400 & 0.200 & 0.700 & 0.500 & 0.200 & 0.200 & 0.600 & 0.600 & $0.046^{*}$ & 0.800 & 0.700 & 0.600 & $0.037^{*}$ & 0.900 & 0.100 & 0.000 & 0.700 & 0.800 & 0.800 \\
\hline 8 & 0.500 & 0.700 & 0.300 & 0.200 & 0.200 & 0.400 & 0.600 & 0.700 & 0.500 & 0.100 & 0.600 & 0.900 & 0.200 & 0.400 & 1.000 & 0.300 & 0.000 & 0.100 & 0.800 & 0.700 & 0.100 & 0.400 & 0.300 & 0.500 \\
\hline 9 & 1.000 & 0.600 & 1.000 & 0.100 & 0.100 & 0.700 & 0.200 & 0.800 & 0.700 & $0.000^{*}$ & 0.200 & 0.200 & 0.800 & $0.015^{*}$ & 0.900 & 0.800 & 0.000 & 0.100 & 0.100 & 0.800 & 0.000 & $0.003^{*}$ & 0.900 & 0.200 \\
\hline $\begin{array}{ll}1 & 0 \\
\end{array}$ & 0.300 & 0.100 & 0.900 & 0.100 & 0.800 & 0.600 & 0.400 & 0.300 & 0.300 & $0.001^{*}$ & 0.400 & 0.300 & 0.800 & 0.900 & 0.800 & 1.000 & 0.300 & $0.005^{*}$ & 1.000 & 0.600 & 0.000 & $0.021^{*}$ & 0.600 & 0.300 \\
\hline $\begin{array}{ll}1 & 1 \\
\end{array}$ & 0.200 & 0.200 & 0.600 & 0.700 & 0.100 & $0.005^{*}$ & 0.800 & 0.000 & 0.300 & $0.000^{*}$ & 0.800 & 0.600 & 1.000 & 0.100 & 1.000 & 0.800 & 0.100 & 0.100 & 0.100 & 0.900 & 0.800 & 0.900 & 0.600 & 0.600 \\
\hline $\begin{array}{ll}12 \\
\end{array}$ & 0.200 & 0.800 & 0.700 & $0.01^{*}$ & 0.100 & $0.005^{*}$ & 0.700 & 0.300 & 0.900 & $0.000^{*}$ & 0.700 & 0.800 & 1.000 & 0.300 & $0.02^{*}$ & 0.800 & 0.200 & 0.800 & 0.500 & 0.100 & 0.400 & 0.900 & 1.000 & 0.600 \\
\hline 13 & $.000^{*}$ & 1.000 & 0.300 & 0.400 & 0.000 & 0.700 & 0.900 & 0.700 & 0.800 & $0.050^{*}$ & 0.900 & 0.200 & 1.000 & 0.100 & 0.700 & 0.600 & 0.200 & 0.300 & 0.600 & 0.600 & 0.400 & 0.100 & 0.700 & 0.200 \\
\hline $\begin{array}{ll}1 & 4 \\
\end{array}$ & 0.700 & 0.800 & 0.800 & 0.400 & 1.000 & 0.300 & 0.900 & 0.800 & 0.900 & 0.200 & 0.900 & 0.400 & 0.700 & 0.100 & 0.600 & 0.700 & 0.100 & $0.016^{*}$ & 0.300 & 0.800 & 0.100 & 1.000 & 0.000 & 0.400 \\
\hline 15 & 0.300 & 0.900 & 0.100 & $0.01^{*}$ & 0.600 & 0.200 & 0.600 & 0.700 & 0.500 & 0.100 & 0.600 & 0.800 & 0.900 & 0.100 & 0.300 & 0.500 & 0.000 & 0.200 & $0.02^{*}$ & 0.600 & 0.800 & 0.400 & 0.700 & $0.03^{*}$ \\
\hline 16 & 1.000 & 0.900 & 0.500 & 0.300 & 0.500 & $0.046^{*}$ & 0.300 & 0.200 & 0.200 & $0.000^{*}$ & 0.300 & 0.700 & 0.700 & 1.000 & 0.300 & 0.700 & 0.000 & 0.600 & 1.000 & 0.300 & 0.200 & 0.400 & $0.01^{*}$ & 0.100 \\
\hline 17 & 0.200 & 0.400 & 0.400 & 0.500 & 0.500 & 0.200 & 0.100 & 0.800 & 0.000 & 0.300 & 0.100 & 0.500 & 0.100 & 0.700 & 0.500 & 0.200 & 1.000 & 0.200 & 0.500 & 0.800 & 0.500 & 0.500 & 0.300 & 0.800 \\
\hline
\end{tabular}




\section{Discussion}

The educational intervention was seen to bring about 0.15-to-4.96-unit improvement (ranging from 51 to 0 ) in facilities of the study. This was also demonstrated by the positive trends displayed by almost all demographic characteristics after the intervention. Age, marriage and education were also revealed to be strong indicators of HRQOL. Some scholarly works reported positive trends after educational intervention in the belief and attitude to antihypertensive treatment, whereas others reported insignificant changes. In the very locality of the study, the works of Ganiyu, Erah and Suleiman [18] on HRQOL of hypertensive and diabetic patients reported insignificant improvements after educational intervention. In the work of Magadza, Radloff, and Srinivas in the year 2009 [15], after educational intervention participants were shown to have increased levels of knowledge about hypertension and its therapy as well as their beliefs about medicines, after an educational intervention was carried out $\mathrm{P}<.0001)$. It also revealed that most of the parameters that assessed beliefs about medicines were significantly modified in a positive manner $(\mathrm{P}<.01$ for concerns about medicines, $\mathrm{p}<.01$ for beliefs about the harmful nature of medicines, and $\mathrm{P}<.01$ for the necessity-concerns differential). In their study, improvement in adherence or quality of life was not significant partly because of the short duration of the study. Ozoemena et al 2019 [16] while working on effects of a health education intervention on hypertension-related knowledge, prevention and self-care practices in Nigerian retirees revealed significant improvement in hypertension knowledge $(\mathrm{p}=0001)$ medication adherence $(\mathrm{p}=0.000)$, and time-by-group interaction effects (within-groups) for all the outcomes with small to large effect sizes.

\section{Conclusion}

The study concludes that educational intervention carried out on two health facilities in Bayelsa state of Nigeria recorded insignificant but positive trends in improvement on demographic characteristics and an improvement in quality of life. Age, marriage and education were also indicated as strong indicators of HRQOL. Concordances to the reported results were also observed.

\section{Compliance with ethical standards}

\section{Acknowledgments}

I am grateful for the ethical consent from the three hospitals involved as well as the co-operation of the health team in these facilities.

\section{Disclosure of conflict of interest}

No conflict of interest is associated with this work.

\section{Contribution of Authors}

We declare that this work was done by the author(s) named in this article and all liabilities pertaining to claims relating to the content of this article will be borne by the authors. All authors read and approved the manuscript for publication.

\section{Statement of ethical approval}

The present research work does not contain any studies performed on animal/human by any of the authors.

\section{Statement of informed consent}

Informed consent was obtained from all individual participants included in the study.

\section{References}

[1] Aqeel N, Noman UlH, Sohail R, Maria T, Muhammad S, Riffat Y, Muhammad SZ, Zara A, Sabika R. Health Related Quality Of Life (Hrqol) -. What It Is and How It Is Measured: Studies from the World and Comparison With Pakistan, Indo Am. J. P. Sci. 2018; 05(02).

[2] Felce D, Perry J. Quality of life: its definition and measurement. Research in developmental disabilities. 1995;16:51-74. 
[3] Killewo J, Heggenhougen HK, Quah SR, editors. Epidemiology and Demography in Public Health. San Diego: Academic Press. 2010; 195-205.

[4] Wilson IB, Cleary PD. Linking clinical variables with health-related quality of life. A conceptual model of patient outcomes. JAMA: the journal of the American Medical Association. 1995;273:59-65.

[5] Ebrahim S. Clinical and public health perspectives and applications of health-related quality of life measurement. Social Science and Medicine. 1995;41:1383-94.

[6] Shepard DS. Cost-effectiveness in Health and Medicine. By Gold M.R., Siegel J.E, Russell L.B., and Weinstein M.C. (eds). New York: Oxford University Press, 1996. J Men Health Policy Econ. 1999;2(2):91-2. https://doi.org/10.1002/(SICI)1099-176X(199906)2:2<91::AID-MHP46>3.0.CO;2-I.

[7] Williams B. The year in hypertension. J Am Coll. Cardiol. 2008;51:1803-17.

[8] Kaplan NM, Victor RG .Kaplan's Clinical Hypertension, 10th edn. Philadelphia PA: Lipincott Williams \& Williams: 2010. Google Scholar.

[9] Cutler DM, Everett W .Thinking outside the pillbox--medication adherence as a priority for health care reform. NEngl J Med. 2010; 362: 1553-1555.

[10] Mena-Martin FJ, Martin-Escudero JC, Simal-Blanco F, Carretero-Ares JL, Arzua-Mouronte D, Herreros-Fernandez $\mathrm{V}$. Health-related quality of life of subjects with known and unknown hypertension: results from the populationbased Hortega study. J Hypertens. 2003; 21: 1283-1289.

[11] Bardage C, Isacson D, Ring L, BingeforsK.A Swedish population-based study on the relationship between the SF36 and health utilities to measure health in hypertension.Blood Press. 2003; 12: 203-210.

[12] Alonso J, Ferrer M, Gandek B, Ware Jr JE, Aaronson NK, Mosconi P et al. Health-related quality of life associated with chronic conditions in eight countries: results from the International Quality of Life Assessment (IQOLA) Project. Qual Life Res. 2004; 13: 283-298.

[13] Arslantas D, Ayranci U, Unsal A, TozunM. Prevalence of hypertension among individuals aged 50 years and over and its impact on health related quality of life in a semi-rural area of western Turkey. Chin Med J (Engl). 2008; 121: 1524-1531.

[14] DJ Trevisol, LB Moreira, FD Fuchs, SC Fuchs, Health-related quality of life is worse in individuals with hypertension under drug treatment: results of population-based study, Journal of Human Hypertension volume. 2012; 26: 374-380.

[15] Magadza C, Radloff S, Srinivas S, The effect of an educational intervention on patients' knowledge about hypertension, beliefs about medicines, and adherence, Research in Social and Administrative Pharmacy. 2009; 5(4):363-75,

[16] Ozoemena EL, Iweama CN, Agbaje OS, Umoke PCI, Ene OC, Ofili PC, Agu BN, Orisa CU, Agu M, Anthony E. Effects of a health education intervention on hypertension-related knowledge, prevention and self-care practices in Nigerian retirees: a quasi-experimental study. Arch Public Health. 2019 May 23;77:23. doi: 10.1186/s13690019-0349-x. PMID: 31143446; PMCID: PMC6532220.

[17] Ribeiro CD, Resqueti VR, Lima Í, et al (2015). Educational interventions for improving control of blood pressure in patients with hypertension: a systematic review protocol. BMJ Open. 2015;5:e006583.

[18] Ganiyu KA, Erah OP, Suleiman IA. Health-Related Quality of Life(HRQOL) of Hypertensive and Diabetic patients in Two Tertiary Health Institutions in Niger Delta region, Nigeria. Nigerian Quarterly Journal of Hospital Medicine. 2015; 24(4): 307-310A.

[19] Suleiman IA, Messaih TH, Kpokiri EE. Quality of life of healthy subjects, arthritis and diabetes mellitus patients in Bayelsa state, Niger Delta Nigeria. Tropical Journal of Pharmaceutical Research. 2016; 16 (7):1729-1735. 